\title{
Written Greek but Drawn Egyptian: Script changes in a bilingual dream papyrus
}

\author{
Stephen Kidd
}

Brown University

In a $3^{\text {rd }}$-century вCE Greco-Egyptian letter inscribed on papyrus, a man writes to his friend about a recent dream. He is writing in Greek, but in order to describe his dream accurately, he says, he must write the dream itself in Egyptian; after saying his Greek farewell, he recounts the dream and begins writing in a Demotic hand. This shift in languages entails a number of transitions: a new vocabulary, a wildly different grammar, but also one very important change - a change of script. In this chapter, I will explore the conceptual background between shifting from Greek to Demotic in this letter - not in linguistic or socio-political terms, but in terms of the actual practice of writing and the ideological trappings that accompany each writing-system. I will argue that the two scripts (not just the two languages) inform the letter-writer's decision to choose and elevate Demotic as the proper vehicle for recounting his dream.

I will make this argument in three parts: first, by examining the different ways that these two languages were physically written; second, by 'getting inside' the process of writing an alphabetic (Greek) versus a logographic (Demotic) script; and third, by recreating the subjective experience of the alphabetic - logographic shift through comparative evidence (English and Chinese). Although I do not argue that there is something objectively more lofty or mystical in a logographic script, I do argue that when two cultures come into contact (Greek and Egyptian, English and Chinese) the opportunity is available to compare scripts and to create a hierarchy of uses for them.

This papyrus - a product of Greco-Egyptian cultural contact in $3^{\text {rd }}$-century Egypt - exhibits such a hierarchy in that these different scripts, Greek and Egyptian, appropriate their own registers and purposes. It is possible to see (after examining a) the materiality, b) the writing process and c) the subjective experience) an entire matrix of scriptorial ideology behind this language shift - an ideology which helps to explain why this Greco-Egyptian man, Ptolemaios, chooses Egyptian for his dream content. After all, he is making the transition from every-day affairs to

\section{How to cite this book chapter:}

Kidd, S. 2013. Written Greek but Drawn Egyptian: Script changes in a bilingual dream papyrus. In: Piquette, K. E. and Whitehouse, R. D. (eds.) Writing as Material Practice: Substance, surface and medium. Pp. 239-252. London: Ubiquity Press. DOI: http://dx.doi.org/10.5334/bai.l 
the religious visions of the night, and as much as cultural and religious reasons might help to explain this shift, the actual, physical writing does as well. The difference between these two scripts is that of the mundane real world and that of the symbolic dream world - the Greek written, but the Egyptian drawn.

\section{The Papyrus}

Here are the translations of the central fragments of the $3^{\text {rd }}$-century вСЕ papyrus letter (translation with minor changes from Renberg and Naether 2010):

[In Greek]

\section{P.Cairo 10328 , recto}

...it also (?) seemed good to me that I should fully inform you about my dream, so that you will know in what ways the gods know you. I have written below in Egyptian so that you will know precisely (aigyptisti de hypegrapsa, hopôs akribôs eidêis). When I was about to go to sleep, I wrote two short letters, the one concerning Taunchis the daughter of Thermouthis and the other concerning Tetimouthis the daughter of Taues, who is the daughter of Ptolemaios, and yet one more...

\section{P.Cairo 30961, recto}

...pour a drink for (or anoint) yourself, in which manner I too celebrated a fine (kalên) day. Farewell. Year 2, Phaophi 26.

[At this point in P.Cairo 30961 recto, Ptolemaios starts to write in Demotic] I saw myself in a dream in the following way: I am standing at the doorway of the sanctuary. A priest is sitting there, and many people ( remetch) are standing beside him. The priest spoke to the people who were standing there: “...”

\section{P.Cairo 30961, verso}

...I spoke [to the] aforementioned [prie]st: "The man of Pamoun - who is it?" He said: "It is Nebwotis". See, the answer which they gave me: the man of Pamoun whom he named: "He is /That's life". He says: "Taunchis", (and) she said to me: "The man of Pamoun, who is it?" He said, "Nebwotis is it, who has said it". The one who is there says: "A woman is it outside giving to me..."

This letter has been dated to the $3^{\text {rd }}$ century всE, and has been conjectured to be from the Fayum region, although the most recent editors have cast doubt on this provenance (Bagnall and Derow 2004; Goodspeed 1902; Renberg and Naether 2010; Spiegelberg 1908; Wilcken and von Mitteis 1912; Witkowski 1911). If it is indeed of a $3^{\text {rd }}$-century date, it must be late, due to the use of the reed pen for writing the Egyptian, which suggests a date after 230 все (Depauw 1997: 83). The question of interest for this papyrus is why Ptolemaios switches from Greek to Egyptian in order to describe his dream. He writes "I have written below in Egyptian, so that you may accurately understand". But does this mean that Akhilles' Greek was not proficient? As Wilcken and von Mitteis suggested a century ago, such a conclusion would be absurd, since if Ptolemaios had thought Akhilles' knowledge of Greek was inadequate, he would not have written him a Greek letter in the first place (Wilcken and von Mitteis 1912: 74). It seems that the reason for the language shift must be due to something other than language competence. One could identify cultural reasons for the shift 


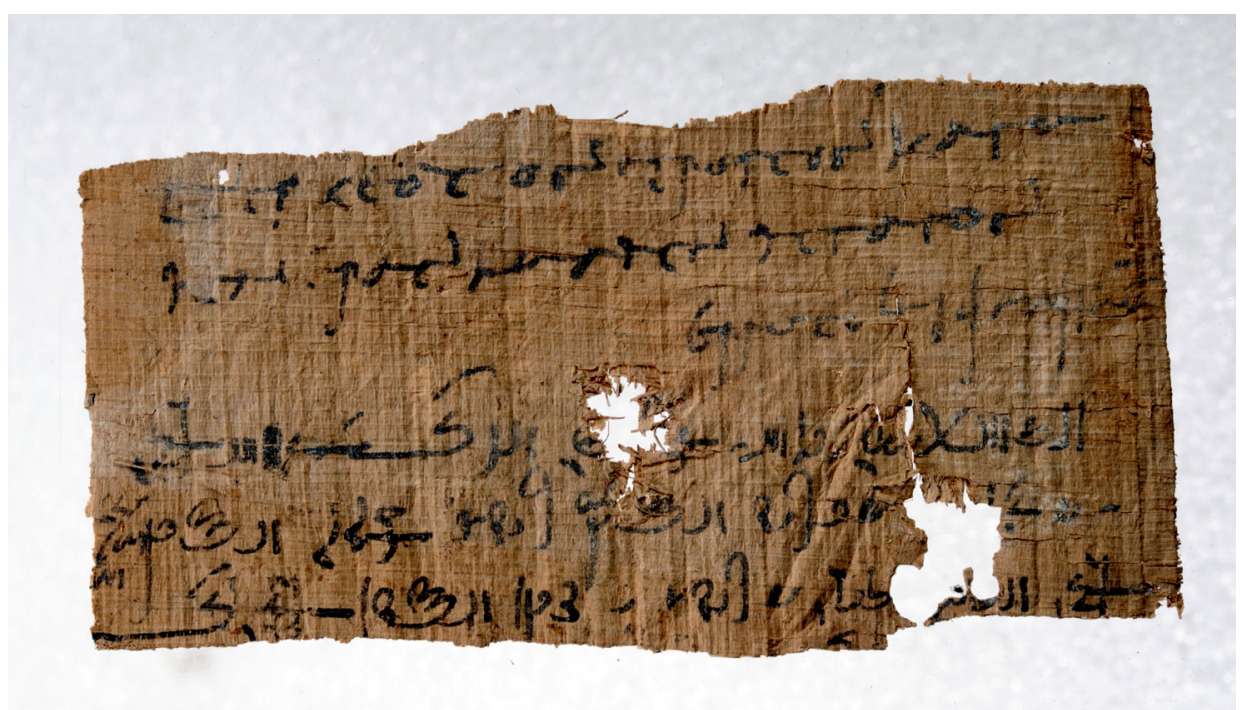

Figure 1: P.Cairo 30961 recto. Photograph Ahmed Amin, Egyptian Museum, Cairo.

(e.g. that when bilinguals discuss religious topics in Ptolemaic Egypt, either in spoken or written form, they might tend toward using Egyptian rather than Greek). Or one might identify linguistic reasons (e.g. that in order to interpret a dream properly one must look to the words themselves a style of dream interpretation found in both Greek and Egyptian dream-interpretation manuals). I consider such possibilities elsewhere (Kidd 2011). Here, however, rather than pursuing linguistic or religious reasons, I would like to consider the physical influences that were present when Ptolemaios made this language shift, especially regarding the scripts themselves and the material practice of writing these two scripts. Arguably, the material of the writing surface, the pens, and the ink were just as entangled in Ptolemaios' experience of writing as the immaterial, conceptualized words and sounds, so it is worth considering the materials more closely in their own right. If Greek and Egyptian were generally written with different tools via different embodied practices, could these physical differences inform the language shift? Although language-shifts are generally conceived of as cerebral events, the motions of the hand, the materiality of the pens, and the application of ink on papyrus may also drive the transitions of language, not as passive accompaniments, but active agents. It is to these materials I now turn.

\section{The Materiality of Writing Greek and Egyptian}

When Ptolemaios wrote this letter he used a pen made of reed, both for the Greek and the Egyptian parts (Figure 1). But this was not usually the case in the $3^{\text {rd }}$ century. Rather, there seems to have been a strict division between the tools that were used to write Greek and the tools that were used to write Demotic. A Greek writing Greek would generally use a pen made of reed while an Egyptian writing Egyptian would use a pen made of rush. Although the differences between these two pens have been described already in detail by Tait (1998) and Clarysse (1993), it is worth giving a quick overview again here.

When a Greek wrote Greek in $3^{\text {rd }}$-century вCE Egypt, the process of writing his or her language was quite different from an Egyptian writing Egyptian. The pen that a Greek used was made from Egyptian reed (Figure 2), to be exact the stem of the Phragmites communis (Tait 1988: 477). These reed stems could be cut as long as $26.5 \mathrm{~cm}$, and after drying, would be sharpened to a broad 


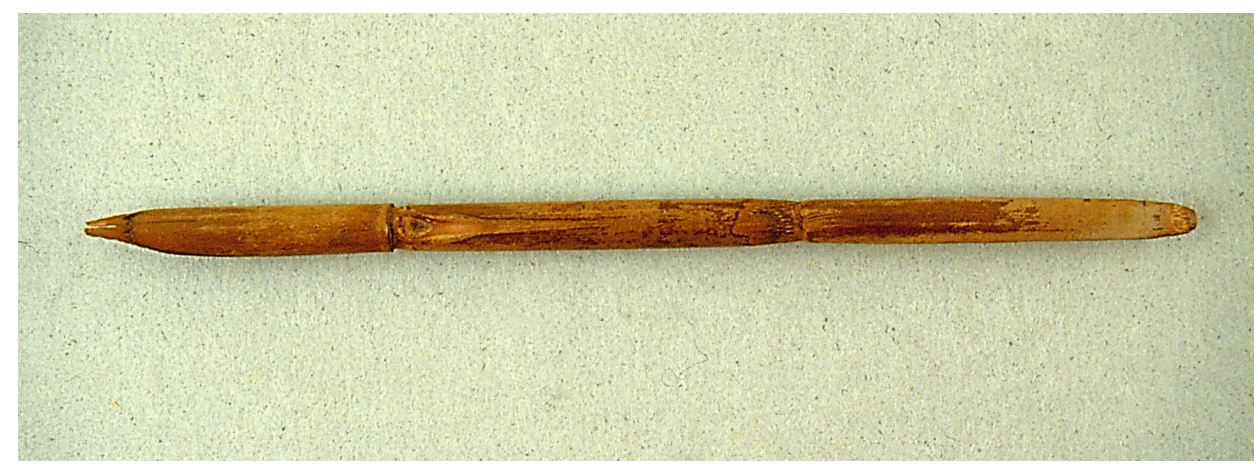

Figure 2: Reed pen, Roman period, Karanis. KM 3820, Kelsey Museum of Archaeology, University of Michigan.

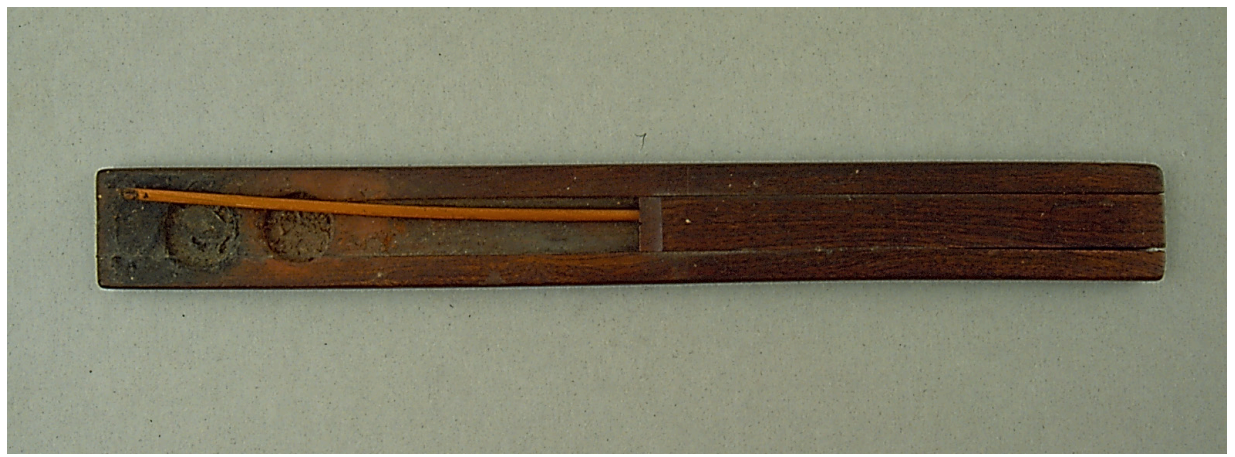

Figure 3: Rush pen inserted into holder built into palette. KM 1971.2.184 a-b, Kelsey Museum of Archaeology, University of Michigan.

point, and split at the nib in the same way that quills were later used. When the reed would lose its point it would have to be sharpened again in order to function properly (in a papyrus containing verses from the Greek playwright Menander, this reed sharpening occurred roughly every 50 lines, Turner 1971: 8). In this process, the originally long pen would eventually be whittled down pencil-like to a stump of some $6.0 \mathrm{~cm}$ long. One such reed-stump was even found lengthened with a bit of wood (Lucas 1934: 133).

The Egyptian pen (Figure 3), on the other hand, was really not a pen at all, but rather a brush. Not made from thick reed (the diameter of which was about $1.0 \mathrm{~cm}$ ) but from the much thinner Egyptian rush (about $0.15 \mathrm{~cm}$ in diameter, or $\sim 1 / 5$ the thickness of the reed). The rush, or to be exact, the Juncus acutus (Tait 1988: 477), grew generally in Egyptian salt marshes, and its stem was cut to a similar length as the reed (specimens found from 16-23 cm, Lucas 1934: 133). But rather than being sharpened like the reed, it was cut diagonally at the end, bruised and frayed (some say by chewing, but others note that chewing is both unnecessary and, considering the ink, messy) in order to work the naturally-occurring fibers into brush-like form.

These different pens required different accoutrements. The Greek scribe used the reed with a metallic-based ink and an inkwell (Figure 4): once the ink was absorbed in the nib, the writer held the pen at an angle, and wrote (from left to right) until the ink dried up, at which point the pen was dipped back into the inkwell and the process started anew. The image of this writer is not far off from modern writing (before the invention of the fountain pen which required the hand to rest on the writing-surface in order to produce a sharper pen angle) - the dipping in the inkpot, the holding of the pen at the angle, etc. For the Egyptian scribe, however, the process of writing 


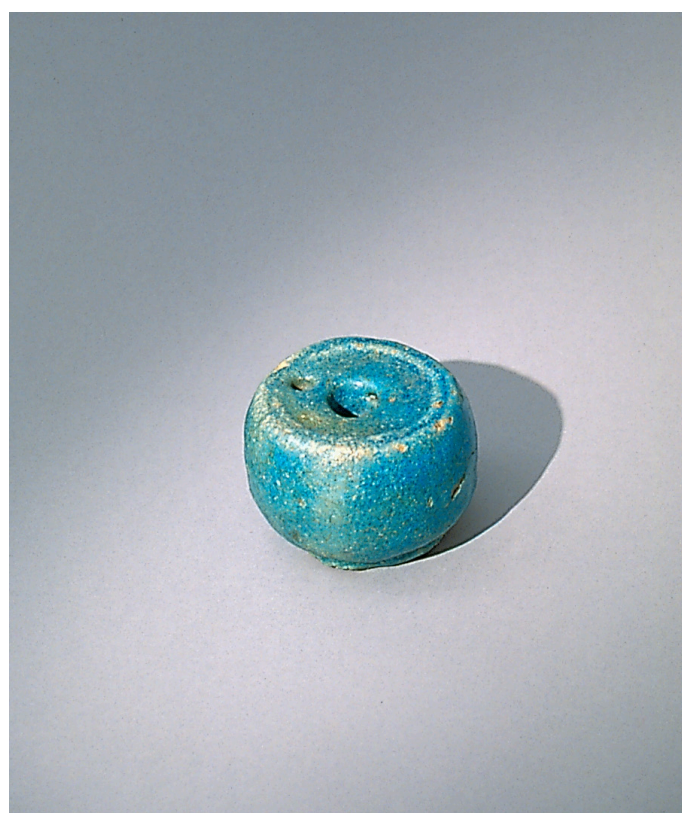

Figure 4: Faience inkwell, Ptolemaic-Roman period, Fayoum. KM 4969, Kelsey Museum of Archaeology, University of Michigan.

is closer to our associations not of writing, but of painting - especially watercolour painting. For one, the brush-like rush was not used with an inkwell, but a palette (Figure 3), which held a cake of black, carbon-based 'watercolour' in one oval (a mixture of black pigment from charred organic materials and a gum arabic binding) and a cake of red 'watercolour' in the other (red pigment from iron oxide; see Nicholson and Shaw 2000: 238, and Clarysse 1993: 189 for the differences between Greek metallic based ink versus Egyptian carbon-based ink). The writer then applied water with the brush to the 'watercolour', and then proceeded to apply this ink to the surface (papyrus, ostracon, etc.), not holding the pen at an angle as one did with the reed, but holding the brush vertically, with the hand floating freely over the papyrus ("about $5 \mathrm{~cm}$ from its writing end" [Clarysse 1993: 189]), writing right to left.

The differences in these two types of pens may have even affected how the scribe sat when he or she wrote. From an early Egyptian sculpture known as 'The Seated Scribe' (Louvre E3023), it can be seen that writing ( $c .2500 \mathrm{BCE})$ was practiced sitting on the floor in a cross-legged position - the scribe stretching his kilt tautly across his knees in order to provide support for the papyrus. Although it has been supposed that this posture of writing continued not just for later Egyptian scribes but for Greek ones as well, Turner makes the important observation that the Greek reed pen, unlike the Egyptian rush, was hard, sharp, and, due to the pressure it sometimes required, could easily have punctured the papyrus if it were not supported by some harder surface. He suggests that some hard material such as a writing-board might have been needed to support the reed's pressure: and indeed, there have been finds of small writing desks (Figure 5), as well as depictions of Greek scribes writing while seated on chairs (see Turner 1971: 7-8 for references).

Thus, there are a number of differences between the material practices of writing for an Egyptian and a Greek - not just regarding the pens used (rush, reed), but also the accoutrements (inkwells, palettes), the holding positions, and possibly even the sitting positions for the writing as well. With such striking physical differences between these two practices of writing, one wonders whether there were also conceptual differences between Egyptian rush-writing and Greek reed-writing. 


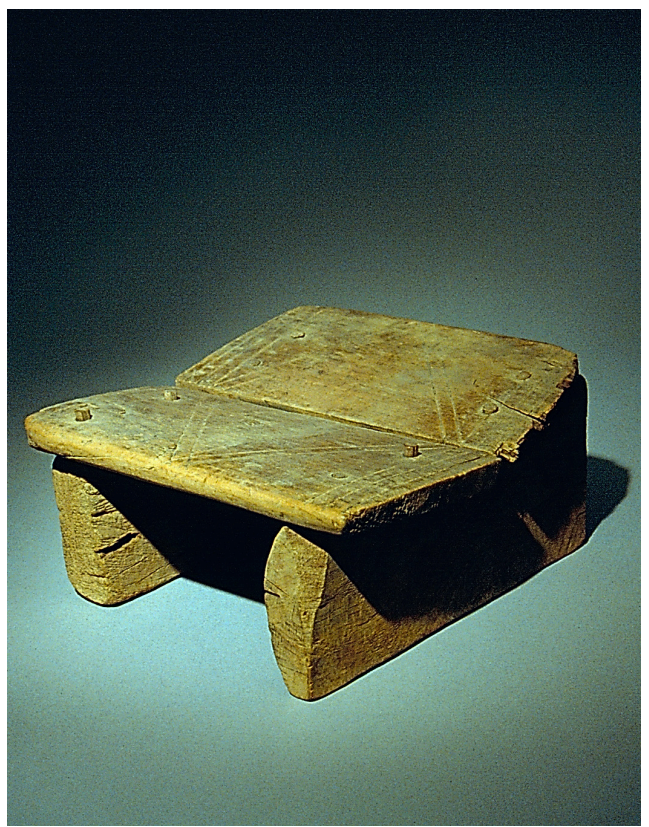

Figure 5: Wooden writing table, Karanis. KM 2.4802, Kelsey Museum of Archaeology, University of Michigan.

That is, would Ptolemaios, for example, in writing the Egyptian of this letter with a reed and not a rush, have considered himself to be writing in a 'Greek' way? Would such practice have seemed strange to him? During this same period when Ptolemaios was writing this letter with a reed pen, Egyptian scribes elsewhere were just beginning to abandon the rush pen and adopt the reed for writing Greek, the language of the new ruling class (although Egyptian documents still were written with the rush); gradually, the reed pen came to dominate more generally (by the $2^{\text {nd }}$ century CE, both Greek and Egyptian were written with the reed pen; Clarysse 1993; Depauw 1997: 83; Tait 1988: 481). But in Ptolemaios' day, there was still a fairly strict division between writing Egyptian with a rush and Greek with a reed.

One would expect that if there were truly a different conception of 'Greek' and 'Egyptian' writing - i.e. that Greek is a language to be written with a reed, and Egyptian a language to be 'painted' with a rush - Ptolemaios would have switched pens for the Egyptian portion of the letter. But this would have been extraordinarily inexpedient: understandably, when Ptolemaios switched to Egyptian for his dream, he did not put away the reed, clean the inkpot, locate an Egyptian rush, cake some watercolour onto a palette, fill up a clean pot with water, and begin writing again. Instead he continued on with the reed pen - and the same thing seems to have happened in P.Duk.Inv. 675 (cf. Sosin and Manning 2003). Yet that expediency, I think, ought not erase those two images of Greek 'writing' and Egyptian 'painting. Even at the moment when transition between the two practices seems most effortless (i.e. when the Egyptian language is written with a Greek reed), this does not mean that the images and cognitive associations of 'Egyptian' and 'Greek' writing disappeared. One might think, for example, of melodies associated with certain instruments, or sculptures associated with certain materials. The ease of transference for the immaterial aspect of those melodies or forms does not abrogate the memories of the materials associated with those forms, or the performances associated with those melodies. Although now lost behind the remaining object, when Ptolemaios shifted from Greek to Egyptian, it seems likely that there was a vast network of different images and physical memories flooding his mind, not just those less material aspects of communication (e.g. meanings, sentences and sounds). 
The reason why raising such questions is important, is that it helps one to begin to think of language in more material terms, and language-shifts not as purely cerebral events, but as events interconnected with physical practices and the memories of such practices. For the Greco-Egyptian of Ptolemaios' day, the processes of writing Greek and Egyptian were highly different - while Greek was 'written', Egyptian was 'painted' - and so Ptolemaios, in his language shift, was not just choosing between two different languages, but between what were usually two very different practices of writing. Of course, there is more to this notion of 'painting' Demotic than just its material practice: there is also the script itself. Like Egyptian trilingual inscriptions where a hierarchy of scripts is on display - a relief picture at the top, hieroglyphs at the second tier, Demotic on the third and Greek on the fourth - certain scripts claim a higher level of visuality than others (i.e. certain scripts are logographic rather than alphabetic, creating images rather than spellings). It might be claimed that there are two aspects to 'painting', then: not just the painting materials used to 'paint' Demotic, but the Demotic script itself which demands a higher level of visuality than an alphabetic script like Greek. This difference in scripts is the subject of the next section.

\section{Alphabetic Versus Logographic Scripts}

In Chapter 6 of his Interpretation of Dreams, Sigmund Freud imagines dreams as languages containing both alphabetic scripts and pictographic ones. Discussing "the Dream-Work", he writes:

The dream-thoughts and the dream-content are presented to us like two versions of the same subject-matter in two different languages. Or, more properly, the dream-content seems like a transcript of the dream-thoughts into another mode of expression... The dream-thoughts are immediately comprehensible, as soon as we have learnt them. The dream-content, on the other hand, is expressed as it were in a pictographic script, the characters of which have to be transposed individually into the language of the dreamthoughts... (Freud 1954: 277).

Freud's metaphor of two different dream-languages rides not on how the language of dreams is spoken, but how it is written: the same subject matter is being described first in an everyday script, second in a pictographic one. Ptolemaios' bilingual letter is in some ways a bizarre realization of Freud's dream-script: in order to describe his dream, Ptolemaios shifts from an alphabetic script (Greek), to another, non-alphabetic form of writing (Demotic Egyptian). Although Demotic is a not a pictographic script, it is derived from one (early hieroglyphs), and the way in which it was written was fundamentally different from Greek. In this section of this chapter, I will consider Ptolemaios' language-shift vis-à-vis the actual movements of writing. After analyzing two words from the papyrus (one Greek, one Demotic), I will consider the alphabetic and logographic scripts in terms of the painting-versus-writing spectrum discussed above, only now in terms of picture-versus-script. If there is a sliding scale between word and picture (as some Egyptian trilingual decrees suggest), Greek and Demotic may have been perceived at different points on that scale.

Greek is an alphabetic script while Demotic was derived from earlier hieroglyphs and thus was something rather different. From original pictograms, hieroglyphs evolved into a much more complex script which was able to represent sounds as well as ideas. The script even developed an alphabet of sorts which could clarify the meaning of certain words and supplement the Egyptian vocabulary with loan words and foreign names. But one must be clear about this 'alphabet': Demotic's alphabetic elements never formed an alphabet in the Greek sense, learned front-toback at the beginning of school. It was never an alphabet which - like the Periodic Table - could break down any word of the known world into its natural elements. Indeed, an Egyptian person (before the invention of Coptic) could never have constructed a sublime alphabetic concept like 
'I am the Alpha and the Omega'. Thus, although there was something of an alphabet in Demotic, it was used as more of an auxiliary tool than the fundamental basis of the written language. What makes Demotic interesting for this dream letter is its logographic aspect - so the distinction between alphabetic and logographic is worth outlining in closer detail here.

On the fragment of papyrus where the shift between Greek and Egyptian scripts can actually be seen (Figure 1), the first three lines are written in Greek. To take an example from these lines is the Greek word 'kalên' which means 'fine, beautiful': in order to write 'kalên' Ptolemaios needed to write a kappa which he smoothly linked to an alpha, and then to a lambda; after a new break with the eta, he finished with the $n u$. In 'kalên' each of the five letters is its own self-standing element that is, when Ptolemaios finished the strokes required to write the kappa, he proceeded on to the alpha, and so forth (cf. Johnston, this volume). In Demotic it is quite different: to take an example from the letter one can see the word ' remetch' which means ' $m a n$ '. In Demotic it is written as ' ', The word is two syllables, but ' $r$ ' is all that needs to be written: it simply means 'man', and there are no smaller elements into which it can be divided. To write this logographic word in the Greek alphabet would require nine letters (anthrôpos). Of course, ' $\mu$ ' is an unusually simple word for Demotic as far as writing is concerned and usually many more strokes are required, but a simple example is useful here. When Ptolemaios dragged the reed pen across the page to write Greek, the telos of his writing can be placed not at the level of the word but that of the letter (or perhaps the syllable, cf. Cribiore 1996: 40-42): here he pulls the stroke downward to make the spine of a kappa, and here he has finished the kappa and moved onto the alpha. Each motion of the pen is teleologically driven not by the word but by the alphabetic letter. But with the Demotic word ' $r$ ', where is the telos? Here Ptolemaios drags the line downwards to create the spine of what? At what point has he reached some sort of half-way point, like a 'rem' or a 'metch'? At no point. Not until the whole word, the whole image is complete is there any sense of resolution or finality.

One might envision a spectrum between image and alphabet, drawing and writing. Although neither of these scripts, Greek nor Egyptian, provide actual pictures, if one considers such scripts on a sliding scale (from writing to drawing) would the two scripts be located at different points? For the former, the motions of the pen find their telos in an alphabetic letter, for the latter the motions can find no other telos than the 'man' himself standing before the writer's eyes ' $\%$ '. It may seem like a minor point but it is an important one: the script mediates the relationship between (literate) persons and their language. Certain ideas, anxieties, and creative possibilities are simply not available to a Greek writer but available to an Egyptian (and vice versa) for no reason other than their scripts. When one turns to Demotic's predecessor script, Hieroglyphs, some of these script-based thoughts can be inferred. Penelope Wilson writes of the Pyramid Texts of Dynasty 5 inside the burial chambers of kings Teti and Pepi I where animal hieroglyphs were individually mutilated (Wilson 2003: 71): "The animal signs were written without legs, birds had their heads cut off, knives were inserted into the bodies of snakes or crocodiles, human figures were drawn incomplete, etc.", in the fear that these hieroglyphic images would come to life and threaten the dead person in his or her eternity. Is such a fear possible for a Greek, or for anyone with an alphabetic script? Alphabetic scripts have their own use of damnatio memoriae, but the fear of the word can never be realized in such a way that the words qua images become the animals they appear to be. Egyptian, at least in hieroglyphic form (which again is the ancestor of the Demotic script), is rooted in a visuality which an alphabetic script cannot attain. Furthermore, this visuality is both conscious and manipulated in that sliding scale between words and art. For example, in Egyptian there are a number of so-called 'determinatives' - pictures which clarify visually a word's meaning (note the $\subset$ determinative to the left of the central tear in Figure 6). If one can imagine English being written not with an alphabet but 'Egyptianly', determinatives would make it easier to differentiate between two homophonic words such as the verb 'to bear' and the animal 'a bear. By adding a determinative - a little picture of a bear next to one word and a picture of a person carrying something next to the other - the homophones can be distinguished. These 


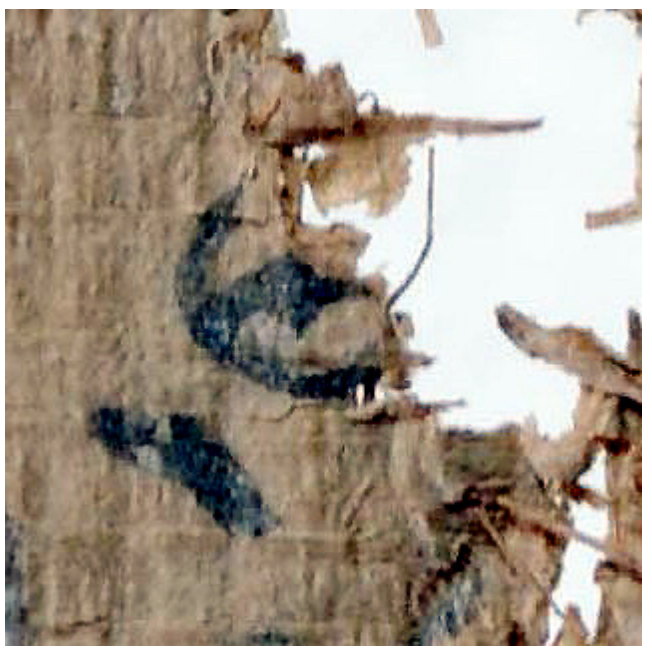

Figure 6: P.Cairo 30961 recto (detail): the 'eye-determinative' at the end of the Egyptian word for 'dream'.

are clearly visual elements of writing. But what is interesting is that these elements were not just passively received as a natural part of writing and reading but were often actively played with in 'art' (used in a non-westernizing general sense; cf. Baines 1989). For example, there are a number of Egyptian pictures and sculptures with inscriptions bearing words without determinatives - a grammatically unusual feature. Why is this so? Because the picture or the sculpture itself also functions as one giant determinative for the inscription's 'ungrammatical' word. Rather than writing a determinative of a man or woman, the composer of the inscription used the sculpture as script, as the determinative (cf. Wilson 2003: 68-83). This is an entirely different 'art of writing', in that the boundaries between art and writing - much stricter in alphabetic scripts - become permeable to the extent that it is difficult to locate exactly where the writing stops and the mimetic visual art begins (cf. Baines 1985; 1989; 1994).

In contrast, alphabets, although less amenable to certain kinds of visual play, allow for possibilities that logographic scripts cannot have. Not just expressions like 'I am the Alpha and Omega' or a feeling for the divisibility of the written world into its constituent elements (in Greek, stoikhea can mean both 'letters' and 'physical elements'), but alphabetic scripts give rise to their own sorts of games or delusions. The $2^{\text {nd }}$-century CE Greek writer Athenaeus $(10.453 \mathrm{c})$ reports an 'Alphabetic Tragedy' written by the comic playwright Callias in $5^{\text {th }}$-century BCE Athens - probably produced shortly after Athens' alphabet reform in 403 вCE (Slater 2002). In the play, the members of the Chorus are individual letters and the songs they sing consist of letters combining into syllables: a familiar school exercise for literate Greeks (for early alphabet education, cf. Cribiore 1996: 37-40). It seems like it would be dreadful to listen through every single syllabic combination (e.g. 'beta alpha ba' or 'gamma alpha ga', etc.) but since it was set to tragic music and probably a tragic parody, it must have been at least mildly amusing. But what is important here is that this Greek fixation on sound and elemental combinations could not have had the same force for an Egyptian - for even though Egyptians, too, could 'spell out' sounds, much of the logographic aspect of their script stood beyond alphabetic elements in a realm of pure visuality.

It may be argued that graphical boundaries ought not be so starkly drawn, since if one only reads a little further in Athenaeus (10.454a-f) visual aspects of the Greek alphabet can be found. Athenaeus quotes three scenes (from Euripides' Theseus, Agathon's Telephus, and a play of Theodektos) where an illiterate man (agrammatos) describes an inscription to someone else (inscriptions of the name 'Theseus'). Since the man is illiterate he can only describe what the 
letters look like - e.g. a 'Scythian bow' or a 'lock of hair' which would represent a sigma. But it must be emphasized that this is a playfully staged experience of illiteracy, not reading. The letter sigma has nothing to do with these objects, and this is part of the dramatist's game. But logograms, although they, too, are not pictograms, still function on that plane of visuality that alphabets do not: the image is the word. To read Greek in the way that these illiterate characters do is to misread and to misunderstand the basics of letters forming syllables. This foreign way of reading is what is being staged in these three plays as an emphasis on how unusual it is to locate such a visual dimension in Greek.

Regarding the particular case study of this chapter, when Ptolemaios wrote the line "aigyptisti de hypegrapsa, hopôs akribôs eidêis", what precisely did he mean? There are two points of pressure in translating this Greek sentence in this particular context, two points where a reader might play with translation. The first is this verb 'hypegrapsa' a compound of the verb 'graphein': on the one hand, it can mean 'to write', on the other it can mean 'to paint, draw'. The second is this verb 'eidêis': on the one hand it means 'to know', on the other it can mean 'to see'. In other words, if one wanted to be perverse, one could translate the sentence as "I have sketched out below in Egyptian, in order that you see accurately". This is, of course, not what Ptolemaios had in mind but it raises the question: where exactly does Egyptian lie on that spectrum of meanings for graphein, where between writing and painting? When Akhilles read the Demotic part of the letter, did he change positions on this hypothetical scale of reading versus seeing? When compared to Greek, one can perceive a heightened visuality between Egyptian logograms and alphabetic permutations.

But it may be questioned 'perceivable to whom'? Who would consider one script more 'visual' than another, and who would consider 'visuality' as a criterion for scriptural hierarchy? Ancient testimony is scarce for Greek views of Demotic or vice versa. Although a number of Greeks discuss Egyptian scripts - Herodotus (2.36), Diodorus Siculus (3.3), Chairemon (fragment 12), Clement of Alexandria (Strom. 5.4), Horapollo, etc. - their understanding is far from the bilingualism suggested by this letter. Furthermore, it is one thing to consider hieroglyphs' relationship to an alphabetic script, and quite another to consider a much later cursive descendant of those hieroglyphs (i.e. Demotic). For that reason, in the next section, I would like to turn briefly to comparative evidence: another alphabetic script (English) coming into contact with another hieroglyphic descendant (Chinese). This comparandum will be helpful for observing the ways in which scriptural hierarchies construct themselves and how such hierarchies of visuality become articulated (especially when the original hieroglyph is no longer recognizable, as in Demotic and Chinese.) Possibilities emerge of how Ptolemaios might have subjectively experienced these two scripts, Greek and Egyptian, whether he experienced them as fundamentally different, and whether he allotted primacy to one or the other.

\section{Subjective Experiences of Chinese Versus English}

Hieroglyphs are one thing, Demotic Egyptian another. The first bears units of language that actually look like pictures (even if they are not pictograms), the second, as a hieroglyphic descendant bears only traces of those pictures. Demotic is a simplified cursive script, and unless one was trained by looking at Demotic and Egyptian side-by-side (perhaps looking, e.g. at trilingual inscriptions), and taught the relationships between words, it is doubtful that the common scribe would actively be able to see the original hieroglyph behind the Demotic scrawl. But even if the original 'pictures' have become so simplified that they disappear, does some element of visuality remain? I would like to argue that it does, and to do so, I will turn to the 'abstract art' of Chinese writing.

Although Chinese writing - which first appears around the $14^{\text {th }}$ century BCE in what is now Anyang, Henan Province (Shizheng 2008) - evolved far from its original hieroglyphs (like 
Demotic), its signs are still often considered representations as though these signs were 'capturing' an original image and expressing that image in an abstract form. So write the curators of the recent 2006 Metropolitan Museum exhibition on Chinese writing titled 'Brush and Ink':

In China, calligraphy, 'the art of writing', is regarded as the quintessential visual art, ranking above painting as the most important vehicle for individual expression. As such, calligraphy may be appreciated in much the same way as some abstract art - by following the artist's every gesture, re-experiencing the kinesthetic action of creation as preserved in the inked lines. This installation will trace the 1,600-year history of brush writing from its genesis as a fine art in the 4th century A.D....to its recent transformation...into a form of abstract art (Metropolitan Museum of Art 2006).

To what extent can alphabetic writing be considered an 'abstract art'? I do not mean to what extent can alphabetic writing be used within abstract art, as for example, American artist Cy Twombly does. I mean the writing itself being viewed not as a 'spelling out' of the word but somehow an abstract representation of the word. One would be hard-pressed to find testimony of alphabetic 'representation', but it is precisely this idea of abstract representation versus 'spelling out' which frequently occurs in the Chinese-English testimonia.

Whether it is a native Chinese speaker who learned English or vice versa, the Chinese language assumes a certain artistic, aesthetic or even spiritual primacy over English - not for how the language sounds, but for how it is written. What is most interesting is that this primacy is rarely articulated in any objective way, i.e. "Chinese script is a more aesthetic / spiritual style of writing because of $\mathrm{x}, \mathrm{y}$, and $\mathrm{z}$ " but rather the testimonia often take recourse to metaphor as though the writer cannot quite grasp why one language / script is loftier than the other. There is good reason for this: quite simply one language / script is not loftier than the other. Both languages (English and Chinese, or Greek and Egyptian), when isolated from each other carry out the same mundane functions of daily transaction. But once in contact with each other, (creative) comparisons arise of how it 'feels' to write or read the script of one language rather than the other.

Take, for example, the English poet Ezra Pound. Learning an alphabetic script first and only later learning a logographic one, Pound describes the logographic language in almost mystical terms - not for how it sounds, not for its spoken grammar, but for how it is written. For Pound, in the $A B C$ of Reading, the Chinese language consists of pictures based on sight, not sound (Pound 1951: 20), which certain people do not need to learn but can immediately recognize: "the Chinese ideogram is based on something everyone knows" (Pound 1951:22). It is the ultimate language of poetry, because instead of defining, e.g. the term 'red' through increasing logical abstractions (e.g. 'color', 'hue,' 'spectrum'), it "puts together abbreviated pictures of a rose, a cherry, iron rust, a flamingo". Pound's ideas in this book are largely derived from Ernest Fenollosa's Essay on the Chinese Written Character to which Pound ascribes a profound importance. Fenollosa also soars to lofty heights in describing the potential of the Chinese character's visuality: "...Chinese notation is something very much more than... arbitrary symbols. It is based upon a vivid short-hand picture of the operations of nature" (Fenollosa and Pound 2008: 80). While the spoken word depends on "sheer convention", the Chinese method proceeds upon "natural suggestion". The objectivity of Pound's and Fenollosa's discussions of Chinese - as though it were a language beyond grammar and derived from nature itself - naturally comes under fierce criticism from those with a better understanding of the language (cf. Kennedy 1958). But the point I want to highlight here is the extent to which the written aspect of the language - which Pound and Fenollosa consider visual due to its non-alphabetic nature - is exalted, to even mystical, spiritual heights.

This spirituality of written Chinese is found in many books on the Chinese character. Rose Quong for example, writes "Chinese written characters reveal the thought process of the Chinese mind and of the universal mind, as well... They have universal appeal because most of these 
characters were originally pictures" (Quong 1973: 9). The causal reason here for the "universality" of the Chinese character is its connection to originally pictographic hieroglyphs (which is something it shares with Demotic). Quong's discussion of the "life-movement" (1973: 9) of the Chinese brush, again, I would argue is nothing objective, but a very particularly articulated subjective experience of comparing two forms of writing - alphabetic and logographic. Diane Wolff (1974: 9) describes the script similarly: "If one understands how Chinese characters are constructed, he can see them better, and see, too, the unceasing poetry of the language to its very roots" and "a Chinese word is really a piece of visual architecture, like a painting, a photomontage, or a collage" (Wolff 1974: 18). If we consider these attitudes from the converse perspective - that is, rather than a native practitioner of an alphabetic language learning logographic script, but vice versa - similar sentiments can be found. Chiang Yee, in his book on Chinese Calligraphy writes that "a Chinese man examining Western calligraphy from the Magna Carta to Bacchylides [will see that it is] elegant but lacking in variety because of the restricted nature of alphabetic forms" (Chiang 1954: 3). To the Chinese or logographic eye, European or alphabetic languages are just "a collection of lifeless letters" (1954: 4) while "a good Chinese character is an artistic thought" (1954: 14) with "each ideogram throwing on the mind an isolated picture... while European words contain no visual ideas". And finally "Chinese is in nature and origin entirely different from any other language. It is perhaps the only pure language in the world". Whether it is West describing East or East describing West, similar sentiments are attested: an exaltation of the logographic over the alphabetic.

Although the grammars of Egyptian and Chinese are very different, there is little need to discuss these differences here since my aim is to explore but one aspect of writing practice as experience - that of the alphabetic script versus the logographic one. The question that remains is whether a Greco-Egyptian could have held similar perceptions. Although there is no firm evidence for Demotic 'calligraphy' as is attested for the earlier Egyptian hieratic script, trilingual GrecoEgyptian inscriptions - which bear a relief at the top, hieroglyphs at the second tier, Demotic on the third, and Greek on the fourth - suggest a certain hierarchy as well as a sliding scale of visuality. Perhaps, Greek too, in comparison with Demotic was perceived to be 'just a collection of lifeless letters'. The contact of logographic and alphabetic scripts forces comparison and hierarchy: the varied perceptions of scripts, as well as that sliding scale of visuality, seem just as applicable to Greek and Egyptian as English and Chinese.

\section{Conclusion}

In this chapter, in order to appreciate the mental processes of a $3^{\text {rd }}$-century Greco-Egyptian bilingual writer, I have focused on the change of this writer's script as well as the material practice of his script. Although this physical practice (and the perceptions of such practice) are not, I would argue, the driving factor behind this code-shift (for it would suggest that if the two were in conversation, Ptolemaios would have not taken recourse to using Egyptian for his dream), it is perfectly plausible to add the script-change as an influence upon the language-shift itself. Ptolemaios' conception of these two languages was not just in their sound, and in their literature, their semantics, syntax and networks of meaning - but his conception of these languages also involved certain material aspects of writing, both visual and experiential. I argued this via three main points: a) that the scripts of each language were bound up in very different material practices (Egyptian rush, Greek reed) even if in this particular instance only the reed was deployed; b) that a logographic language is fundamentally different from an alphabetic language (the former pushing the Greek term 'graphein' into more artistic, visual terrain); and c) that when two cultures collide (as here Greece and Egypt) each language takes on certain subjective experiences which would not exist were the cultures to remain separate. As with English and Chinese, the logographic script 
can assume a certain spiritual or natural primacy over the typically more mundane alphabetic script. Taking these three points together then, I suggest that Ptolemaios' shift was informed not only by the (audible) languages as they were processed in his brain, but very much by the scripts themselves as they were experienced in the motions of his hands, the movement of his eyes, and the material objects he used to interact with these scripts. This case study suggests that code-shifts, although probably not caused by, can at least be informed by the materiality of writing - the way writing is experienced physically, the way it appears on the page, and the images of 'writing' that appear in the mind of someone engaged in such practice.

\section{References}

Bagnall, R. S. and Derow, P. 2004. The Hellenistic Period: Historical sources in translation. Malden, MA: Blackwell. DOI: http://dx.doi.org/10.1002/9780470752760

Baines, J. 1985. Fecundity Figures: Egyptian personification and the iconology of a genre. Warminster: Aris and Phillips.

Baines, J. 1989. Communication and Display: The integration of early Egyptian art and writing. Antiquity 63: 471-482.

Baines, J. 1994. On the Status and Purpose of Ancient Egyptian Art. Cambridge Archaeology Journal 4(1): 67-94. DOI: http://dx.doi.org/10.1017/S0959774300000974

Chiang, Y. 1954. Chinese Calligraphy: An introduction to its aesthetic and technique. London: Methuen and Co.

Clarysse, W. 1993. Egyptian Scribes Writing Greek. Chronique d'Égypte 68: 186-201.

Cribiore, R. 1996. Writing, Teachers, and Students in Graeco-Roman Egypt. Atlanta: Scholars Press.

Depauw, M. 1997. Companion to Demotic Studies. Brussels: Fondation égyptologique reine Elisabeth.

Fenollosa, E. and Pound, E. 2008. The Chinese Written Character as Medium for Poetry. New York: Fordham University Press.

Freud, S. 1954. Interpretation of Dreams. London: G. Allen and Unwin.

Goodspeed, E. J. 1902. Greek Papyri from the Cairo Museum. Chicago: The University of Chicago Press.

Kennedy, A. G. 1958. Fenollosa, Pound, and the Chinese Character. Yale Literary Magazine 126(5): 24-36.

Kidd, S. 2011. Dreams in Bilingual Ptolemaic Papyri. The Bulletin of the American Society of Papyrologists 48: 113-133.

Lucas, A. 1934. Ancient Egyptian Materials and Industries. London: E. Arnold and Co.

Metropolitan Museum of Art 2006. Brush and Ink: The Chinese art of writing, September 2, 2006January 21, 2007. http://www.metmuseum.org/en/exhibitions/listings/2006/brush-and-ink [accessed on 13 August 2011].

Nicholson, P. T. and Shaw, I. (eds) 2000. Ancient Egyptian Materials and Technology. Cambridge: Cambridge University Press.

Pound, E. 1951. ABC of Reading. London: Faber.

Quong, R. 1973. Chinese Written Characters. Boston: Beacon Press.

Renberg, G. and Naether, F. 2010. "I Celebrated a Fine Day": An overlooked Egyptian phrase in a bilingual letter preserving a dream narrative. Zeitschrift für Papyrologie und Epigraphik 175: 49-71.

Shizheng, W. 2008. The Evolution and Artistry of Chinese Characters. In Youfen, W. (ed. and trans.), Chinese Calligraphy. New Haven: Yale University Press, 47-65. 
Slater, N. W. 2002. Dancing the Alphabet: Performative literacy on the Attic stage. In Worthington, I. and Foley J. M. (eds), Epea and Grammata: Oral and written communication in Ancient Greece. Leiden: Brill, 117-129.

Sosin, J. and Manning, J. 2003. Palaeography and Bilingualism: P.Duk.inv. 320 and 675. Chronique d'Égypte 78: 202-210.

Spiegelberg, W. 1908. Die demotischen Denkmäler. Leipzig: W. Drugulin.

Tait, W. J. 1988. Rush and Reed: The pens of Egyptian and Greek scribes. In B. G. Mandilaras (eds), Proceedings of the XVIII International Conference of Papyrology, Athens 25-31 May 1986, Volume 2. Athens: Greek Papyrology Society, 477-481.

Turner, E. 1971. Greek Manuscripts of the Ancient World. Oxford: Clarendon Press.

Wilcken, U. and von Mitteis, L. 1912. Grundzüge und Chrestomathie der Papyruskunde. Leipzig: B. G. Teubner.

Wilson, P. 2003. Sacred Signs: Hieroglyphics in ancient Egypt. Oxford: Oxford University Press. Witkowski, S. 1911. Epistulae Privatae Graecae. Leipzig: B. G. Teubner.

Wolff, D. 1974. An Easy Guide to Everyday Chinese. New York: Harper and Row. 